\title{
Singularidades poéticas da hiperconexão: usos de links eletrônicos em poemas de Marie Bélisle
}

Vinícius Pereira*

\section{Resumo}

Não obstante sua relevância na história das concepções de texto e das tecnologias digitais, a noção de hipertexto frequentemente se esvazia na academia, seja pela inflação semântica a que é submetido para designar dinâmicas de linguagem muito distintas, seja pelo fato de que praticamente todos os discursos na Internet se organizam de modo hipertextual/hipermidiático. Mais especificamente no que tange à literatura eletrônica - campo artístico em franca expansão -, as pesquisas precisam ir além da constatação da organização hipertextual das obras digitais; nesse sentido, devem buscar entender as singulares operações poéticas que o hipertexto pode ensejar e seus respectivos efeitos de sentido. Nessa direção, o presente artigo propõe uma leitura de hiperpoemas de Alter ego, Figures e Lames, desenvolvidos em Flash pela artista québecquense Marie Bélisle. Nessa análise, enfocaremos as operações poéticas engendradas pelo recurso de hiperlinks, para tanto propondo uma categorização de poéticas hipertextuais de alternância, expansão e redistribuição.

Palauras-chave: Hipertexto. Hiperpoemas. Marie Bélisle.

\section{Introdução}

Aos pesquisadores da Linguística, da Literatura e da Comunicação interessou, nos séculos XX e XXI, aproximar-se do objeto texto sob diferentes perspectivas teóricas e metodológicas, culminando numa pletora de conceitos. Um rápido levantamento de alguns dos neologismos formados pela prefixação do substantivo "texto" indica a produtividade conceitual dessas abordagens, sobretudo as de cariz estruturalista e pós-estruturalista, que nos legaram termos como co-texto, pré-texto, pós-texto, subtexto, intertexto, paratexto, metatexto, fenotexto, genotexto, hipotexto, hipertexto etc., os quais indicam não só variadas dinâmicas textuais, mas também distintas formas de lê-las.

\footnotetext{
Professor do Departamento de Letras e do Mestrado em Estudos da Linguagem - Universidade Federal do Mato Grosso. E-mail: viniciuscarpe@gmail.com

Data de submissão: 09 dez. 2019 - Data de aceite: 24 dez. 2019 http://dx.doi.org/10.5335/rdes.v16i1.10352
} 
Entre os neologismos supracitados, talvez um dos que tenha ganho maior escopo semântico e penetração nos vocabulários técnicos de diferentes áreas do saber seja o "hipertexto", conceito que parece ainda hoje incontornável nos exercícios de leitura de textualidades cuja existência esteja atrelada à mídia digital - mesmo que com um sentido bastante distinto do pensado por Genette ${ }^{1}$ (1982) ao discutir relações transtextuais.

Em pesquisas acerca de mídias digitais, o conceito de hipertexto é tradicionalmente evocado para nomear arquiteturas discursivas compostas por blocos de informação (também chamados de lexias, ou nós) interconectados eletronicamente, entre os quais os leitores circulam à sua escolha (LANDOW, 1992). Tal ideia (ainda que expansível para tratar de textos impressos cujas práticas de leitura também sejam não sequenciais, orientadas por rotas definidas pelo leitor, como em enciclopédias, notas de rodapé, sistemas de índices e referências etc.), é sabidamente inspirada no projeto Memex, de Vannevar Bush, que já em 1945 idealizava uma máquina para associação e recuperação mecânica de dados inter-relacionados, servindo a profissionais cujas atividades envolvessem a gestão de um número cada vez maior de informações e que precisassem transitar entre elas rapidamente. $\mathrm{O} \mathrm{Me}-$ mex acabou não se concretizando, mas legou bases para o desenvolvimento de projetos ulteriores, como o Xanadu, de Ted Nelson, que implementou a ideia de hipertexto de maneira muito próxima à que conhecemos hoje.

Não obstante sua relevância na história das concepções de texto e das tecnologias da comunicação e da informação, o conceito de hipertexto muitas vezes se esvazia nas discussões que são feitas na academia, seja pela inflação semântica a que é submetido para designar dinâmicas de linguagem muito distintas, seja pelo fato de que praticamente todos os discursos na Internet hoje se organizam de modo hipertextual e hipermidiático - com conteúdos distribuídos em diferentes porções de uma mesma página, ou em páginas distintas, na forma de textos escritos, vídeos, imagens, áudios e jogos, interconectados por hiperlinks. Desse modo, a simples asserção de que determinado texto on-line é um hipertexto está quase sempre correta, no entanto, flerta com o óbvio.

Tal truísmo constitui, pois, um reincidente obstáculo às discussões sobre literatura eletrônica - campo ainda em formação no que tange à formulação de epistemologias, metodologias e cânones, a despeito do rápido aumento do número de produções literárias digitais, como atestam a constituição de antologias e repositórios especializados, tais quais os três volumes da Electronic Literature Collection, da ELO (Electronic Literature Organization $)(2006 ; 2011 ; 2016)$ e a base 
de dados do projeto ELMCIP - Electronic Literature as a Model of Creativity and Innovation in Practice (2019). Com vistas a um avanço conceitual na área, as pesquisas precisam ir além da constatação da organização hipertextual das obras literárias produzidas para consumo em mídia digital; nesse sentido, devem buscar entender as singulares operações poéticas que o hipertexto enseja e seus respectivos efeitos de sentido.

Com vistas a uma pequena contribuição nessa direção, o presente artigo propõe uma leitura de hiperpoemas das obras Alter ego, Figures e Lames, desenvolvidas em Flash ${ }^{2}$ pela artista quebequense contemporânea Marie Bélisle. Nessa análise, enfocaremos as operações poéticas engendradas em sua obra pelo recurso de hiperlink - aqui entendido como

[...] uma conexão de um elemento (por exemplo, palavra, expressão, imagem etc.) em um documento a outro ponto do mesmo documento, ou a um destino diferente na Web. Hiperlinks são (...) geralmente de uma cor diferente do resto do texto ou são sublinhados; são ativados por um clique no mouse (BUTTERFIELD et al., 2016, sem paginação, tradução nossa).

Para tanto, procederemos, na próxima seção, a uma apresentação panorâmica do campo da literatura eletrônica e do papel que o hipertexto desempenha na área como recurso técnico e estético, definindo, inclusive, subgêneros literários. Na sequência, apresentaremos os exercícios de close reading dos poemas do corpus, a fim de ressaltar os singulares usos de hiperlinks nesses textos (e seus rendimentos estéticos, em relação ao estrato verbal lírico). Por fim, exporemos as considerações finais e as obras referenciadas neste artigo.

\section{Literatura eletrônica, hipertexto e hiperpoesia: notas sobre o campo}

Não há, no meio acadêmico, consenso quanto à nomenclatura utilizada para se referir a produções poéticas em meio digital. Se, por um lado, há autores que usam de forma exclusiva um único termo, outros empregam indistintamente expressões como "literatura eletrônica", "literatura cibernética/ciberliteratura" e "literatura digital". Ainda que reconheçamos que cada um desses adjetivos atrelados ao substantivo "literatura" denota a especificidade do campo por uma associação particular (respectivamente, ao eletrônico, em oposição ao elétrico; ao cibernético, por referência à comunicação entre máquinas; e ao digital, em contraponto ao analógico), o conjunto de obras recobertas pelos três termos é praticamente o mesmo, o que justifica seu uso intercambiável neste contexto.

Mais do que particularidades que cada um desses termos eventualmente possa acarretar, interessa aqui entender a natureza das obras artísticas que eles 
descrevem. Com tal propósito, adotamos a definição de literatura eletrônica postulada pela Electronic Literature Organization (maior grupo mundial de estudos sobre o tema):

[...] obra com um aspecto literário importante que aproveita as capacidades e contextos fornecidos por um computador independente ou em rede (HAYLES, 2009, p. 21).

Conquanto salte aos olhos a relativa vagueza de alguns de seus elementos-chave ("um aspecto literário importante", ou "as capacidades e contextos fornecidos por um computador"), a amplitude da definição garante a possibilidade de abarcar produções artísticas que mobilizam recursos técnicos e estéticos muito variados, proporcionados pelas tecnologias digitais de informação e comunicação. Cabe ressaltar, porém, o relativo consenso entre pesquisadores da área quanto à não abrangência, em seu campo de estudo, de versões digitalizadas de obras concebidas para o suporte impresso, tal qual muitos e-books comercializados por grandes empresas, como a Amazon; textos digitalizados para democratização de acesso e preservação de originais, como no projeto Gutemberg; ou mesmo arquivos produzidos em programas editores de texto convencionais, para práticas de leitura semelhantes às que se dão com livros físicos. Segundo Hayles (2007), a literatura eletrônica é aquela "nascida digital", criada em computador e feita para ser consumi- da também num computador (ou, hoje em dia, em interfaces computacionais popularmente presentes também em dispositivos móveis, como smartphones e tablets).

Dada a variedade de possibilidades artísticas no campo, a maior parte dos pesquisadores leva em consideração, para fins de categorização de subgêneros de literatura eletrônica, as potencialidades da mídia digital mais pronunciadas em cada obra. Autores como Hayles (2009), Funkhouser (2012) e Rettberg (2019) elencam, entre outros subgêneros da literatura eletrônica, a hipertextual que apresenta arquitetura multilinear, distribuída em lexias conectadas por links; a generativa - que consiste em processos (semi)automáticos de produção textual por meio da combinatória de elementos por ação de algoritmos sobre bancos de dados; e a hipermidiática que concatena elementos verbais e não verbais, escritos e sonoros, estáticos e dinâmicos, em interfaces computacionais. Note-se, porém, que muitas obras transitam entre diferentes subgêneros, dada a convergência semiótica e técnica que caracteriza o desenvolvimento atual das tecnologias digitais (JENKINS, 2009).

No caso do presente artigo, interessa particularmente uma análise mais pormenorizada da poesia hipertextual, gênero menos estudado no campo da literatura eletrônica, em que a tecnologia do hipertexto ficou prototipicamente 
associada a formas narrativas. Autores como Barbosa (1998), Hayles (2009) e Rettberg (2019), por exemplo, listam entre subgêneros da literatura eletrônica a hiperficção (ou ficção hipertextual), mas não a hiperpoesia. A invisibilidade desse subgênero poético perante a academia e mesmo sua menor exploração pelos artistas se devem a uma série de causas, entre as quais talvez esteja o fato de que a maior parte das obras impressas de vanguarda consideradas precursoras da literatura hipertextual digital sejam textos em prosa: o romance Rayuela, de Julio Cortázar (1963); o conto "El jardín de senderos que se bifurcan", de Jorge Luis Borges (1941); o projeto filosófico-literário Das Passagen-Werk (escrito entre 1927 e 1940, mas nunca terminado), de Walter Benjamin. Já nessas obras, era evidente certo modo de organização textual que depois seria adotado pelos autores de hiperficção: a distribuição de cenas em diferentes lexias, às quais o leitor teria acesso por meio de um percurso definido por suas escolhas em bifurcações demarcadas no livro.

Ademais, a menor expressividade da hiperpoesia em comparação à ficção hipertextual digital também pode se dever à forma como a literatura eletrônica se estruturou como campo, processo em que se destaca a atuação da casa editorial norte-americana Eastgate, especializada no segmento da hiperficção. Fundada em 1982, a empresa comercializava o software Storyspace, ferramenta que logo se popularizou para a produção de hipertextos. Segundo Hayles (2005), as obras de ficção criadas no Storyspace têm tamanha importância no desenvolvimento da literatura eletrônica que passaram a ser reconhecidas, para fins historiográficos, como integrantes de uma "Escola Storyspace", marcada por potencialidades e limitações dessa ferramenta. Durante muito tempo, os esforços da Eastgate se concentraram na comercialização do Storyspace e de obras de ficção ${ }^{3}$ desenvolvidas no/para o sistema, algumas das quais integram o primeiro cânone da literatura eletrônica, como afternoon, a story, de Michael Joyce, de 1990; Patchwork Girl, de Shelley Jackson, de 1995; e Victory Garden, de Stuart Moulthrop, de 1992. Todavia, a não adaptação da empresa à emergência da Internet e às consequentes mudanças nos padrões de consumo de bens culturais online culminaram na crise da Eastgate e no fim de seu domínio sobre o mercado editorial de hipertextos.

De tal sorte, a hiperpoesia é praticada hoje por poucos artistas independentes que se especializam no gênero, o qual exige um difícil equilíbrio num sistema de forças centrífugas - como a multilinearidade do hipertexto, seu pendor para a narratividade e sua consequente tendência à fragmentação e à dispersão nos percursos entre links determinados pelo leitor (LANDOW, 1992) - e forças 
centrípetas - como a unicidade da imagem poética (PAZ, 1996), a concisão de sua linguagem (COHEN, 1970) e as homologias entre seus diversos estratos fenomenológicos - o visual, o fônico, o morfossintático e o semântico (RAMOS, 1974). Frente a essas conflitantes demandas composicionais que o gênero impõe, cada artista busca caminhos próprios para constituir suas obras, sendo o sistema de articulação de lexias por links eletrônicos o recurso mais recorrente na hiperpoesia para modular tensões nesse compósito de forças heterogêneas.

Ainda acerca do tema da heterogeneidade, cabe ressaltar que Landow (1992), sob uma perspectiva fortemente marcada pelo pensamento pós-estruturalista e pós-modernista, destaca a potencialidade do hipertexto para implementar eletronicamente uma série de colocações que, para ele, antes se limitavam ao nível teórico no âmbito dos Estudos Literários. Incluem-se aí a ideia de différance, de Derrida (2003), pois um hipertexto é sempre diferente de si mesmo, a cada leitura que é feita por meio da escolha de distintos links; a discussão de Barthes (1994) sobre a abertura do texto, em oposição a um suposto fechamento da obra, já que o hipertexto estaria sempre sujeito à ressignificação no ato leitor; os conceitos de intertextualidade e paragrama em Kristeva (2005), dado que um hipertexto é sempre uma rede de textos que se interpenetram e se sobredeterminam mutuamente; e a noção de rizoma, de Deleuze e Guattari (1997), visto que um hipertexto pode vir a ser um labirinto descentralizado e descentralizador do pensamento e do sentido. No caso da hiperpoesia, tais questões seriam permeadas ainda pelas já mencionadas características do discurso lírico, sobretudo a "preservação da pluralidade de significados da palavra sem quebrar a unidade sintática da frase ou do conjunto de frases" (PAZ, 1996, p. 38). Pluralidade e unidade - ou forças centrífugas e forças centrípetas - entrecruzam-se, pois, nas conexões eletrônicas da poesia hipertextual, cujos diferentes expedientes em poemas de Alter ego, Figures e Lames, de Marie Bélisle, são analisados na seção a seguir.

\section{Hiperpoemas de Marie Bélisle: por uma poética da hiperconexão}

Transitando entre muitas linguagens e mídias ao longo de sua carreira, Marie Bélisle tem produções na forma de literatura, artes plásticas, design gráfico e joalheria; boa parte de suas obras estão acessíveis hoje em livros impressos publicados pela Éditions du Noroît, em CD-ROMs e sítios na web, como www. belislemarie.com, www.immortalites. com e www.scripturae.com.

Esta última URL corresponde ao site Scriptura et Caetera, o qual contém os 
hiperpoemas analisados neste artigo e, nas palavras da autora, constitui

[...] uma posição pelas produções experimentais, híbridas e paradoxais... um chamado à curiosidade, à intuição e à inteligência dos internautas (BÉLISLE, 1999, sem paginação, tradução nossa).

Junto a essas palavras, apresentadas ao leitor na tela inicial do site, o leitor encontra as três abas em que se distribuem os trabalhos de Bélisle: Scriptura et machina - "obras literárias informatizadas, animadas e interativas" (BÉLISLE, 1999, n.p., tradução nossa); Scriptura et pictura - "imagens e fotos à guisa de pretextos ou como contexto" (BÉLISLE, 1999, n.p., tradução nossa); e Scriptura et coniventia - "colaborações, efeitos de conjunção e de contraponto" (BÉLISLE, 1999, n.p., tradução nossa).

Ainda na página inicial, a artista informa ao leitor o modus legendi de seus hiperpoemas em Flash: "deslizando sobre a tela, o mouse revelará palavras, imagens, botões..." (BÉLISLE, 1999, n.p., tradução nossa). Com esse paratexto (GENETTE, 1982) explicativo, Bélisle minora a potencial disruptura interpretativa a que estaria exposto o leitor ao navegar em seu site, na medida em que lhe oferece as condições mínimas para, nas palavras de Santos (2013), "dotar-se de um texto a ler"4. Munido dessa lacônica - mas valiosa - instrução, pode o leitor acessar a aba Scriptura et machina, onde encontra, entre outros, os hiperpoemas analisados a seguir.

\section{Alter ego: a alternância hipertextual}

Como nos demais hiperpoemas da autora disponíveis no site Scriptura et Caetera, Alter ego é composto por uma sequência de telas, entre as quais o leitor pode navegar de diferentes formas, sendo a mais óbvia delas o acesso consecutivo por intermédio de hiperlinks sob ícones de algarismos indoarábicos à direita da interface. Tal expediente de organização da informação em blocos sequencialmente numerados, incomum na Internet, reproduz um modo de disposição linear caro à paginação da mídia impressa. Nesse sentido, os hiperlinks numerados acabam refletindo uma escolha da autora por transpor para a nova mídia - o meio digital - uma convenção do suporte pregresso, dinâmica que Manovich (2001) aponta como comum à evolução de todas tecnologias de armazenamento, reprodução e transmissão de dados.

No caso de Alter ego, as telas numeradas são 00 - paratexto à guisa de portada, onde se vê uma breve definição da obra ("um texto reversível de Marie Bélisle”, tradução nossa) e duas imagens que se alternam de modo automático e ininterrupto; 01 - o poema em si, com outros recursos hipertextuais de leitura, como veremos a seguir; e 02 - uma espé- 
cie de mapa dos elementos composicionais de Alter ego. Abaixo do número 02, há ainda um ícone de arroba, que abre uma janela para envio de e-mail à autora, no endereço mbelisle@scripturae.com ${ }^{5}$.

Figuras 1 e 2 - Estados alternados da interface 00

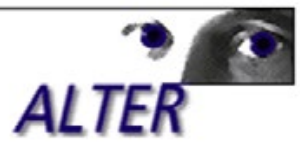

Un texte réversible de Marie Bélisle

Fonte: Bélisle (1999)

Já nessa tela, a alternância entre as imagens de dois olhos em faces idênticas, mas posicionadas de modo distinto e com írises em cores também diferentes, sugere o jogo de permutas e intercalações que rege o funcionamento do hiperpoema. $\mathrm{O}$ título da obra, bem como sua disposição em blocos de letras separados ("alter" e "ego"), sob os olhos que se intercalam, reforça essa ideia: um alterego é um eu que já é outro, ou um outro que ainda sou eu - oscilação entre a identidade e a alteridade que rege uma hiperpoética da alternância nessa obra e implementa um jogo de différance (DERRIDA, 2003) que Landow (1992) já associara à
100

01

02

@
Para fins de análise, apresentamos nas Figuras 1 e 2 a interface a que $o$ leitor tem acesso na tela 00 , em que alternam alguns signos verbais e não verbais.
100

01

02

@
Un texte réversible de Marie Bélisle tecnologia do hipertexto e sua inerente instabilidade.

Na tela 01 , o poema em si, essa dialética entre o mesmo e o outro é implementada por meio de vários hovers ${ }^{6}$, cada um deles vinculado a uma palavra do texto. Contudo, se simplesmente mira a tela, o leitor não nota nenhuma diferença em relação a versos curtos da tradição impressa, pois não percebe a existência de recursos hipertextuais, dada a ausência de marcas tipográficas típicas (efeitos de sublinhado, cor diferente etc.).

A visão é, porém, enganadora - trompe l'oeil a que aludem as cambiantes pupilas das Figuras 1 e 2. Ao deslizar o mouse sobre as palavras do poema - e, 
portanto, ao conectar-se a essa alteridade discursiva que é lábil letra-, descobre o leitor que cada vocábulo esconde um vínculo eletrônico; quando o cursor passa por cima de qualquer um desses termos, desencadeia a substituição da palavra por uma outra, que restava oculta sob a interface. No entanto, a efêmera permuta é desfeita caso o cursor seja arrastado para outra região da tela; assim, a palavra original retorna como se jamais tivesse deixado de lá estar.

Consoante as regras desse ludo visual, não pode o leitor ver simultaneamente ambas as palavras que um hover conecta, tampouco ativar dois deles ao mesmo tempo. Sua leitura é, pois, a de quem assiste à perpétua alternância de signos numa superfície, os quais vão, um de cada vez, sendo permutados por sua contraparte até então irrevelada sob a interface, em dinâmica algo semelhante à que preside à relação in absentia entre quaisquer vocábulos em um mesmo paradigma. Aliás, se Jakobson (1985) já definira que uma das características do discurso poético é a projeção da lógica associativa do paradigma sobre as relações formais do sintagma, Alter ego estabelece, por expedientes hipertextuais, uma poética em que a alternância paradigmática determina a ressignificação de cada verso e amplifica os sentidos do poema como um todo. Este, afinal, revela-se uma potência combinatória de possíveis versos, cujos elementos são comutáveis um a um.
O quadro a seguir apresenta, na coluna 1 , as palavras inicialmente à mostra em Alter ego e, na coluna 2, as palavras que permanecem ocultas até que o mouse corra sobre uma delas. Ambos os conjuntos de versos podem ser visualizados lado a lado pelo leitor na tela 02 , em que a autora justapõe os dois poemas a fim de compor uma espécie de "mapa" das matrizes que se imbricam na leitura hipertextual:

Quadro 1 - Lexias comutáveis em Alter ego

\begin{tabular}{|c|c|}
\hline $\begin{array}{l}\text { Palavras à mostra em } \\
\text { Alter ego }\end{array}$ & $\begin{array}{l}\text { Palavras ocultas na inter- } \\
\text { face e reveladas pelo link }\end{array}$ \\
\hline Dans & Sans \\
\hline l'indicible & l'inaltérable \\
\hline fragrance & fragilité \\
\hline de la colère, & de la luxure, \\
\hline saurais-tu me chérir & pourrais-je te blesser \\
\hline juqu'à ce que & alors même que \\
\hline les larmes du désir & les armes du doute \\
\hline me déchirent & te touchent \\
\hline et te livrent à & et me délivrent de \\
\hline cette double synecdoque: & cette douce métaphore: \\
\hline nous? ${ }^{7}$ & nous? ${ }^{8}$ \\
\hline
\end{tabular}

Fonte: Bélisle (1999)

No poema "inicial", resta patente uma busca da voz poética por um gesto de intimidade por parte do interlocutor, marcada por termos dos campos semânticos das sensações e afetos (como em "fragrance", "colère", "chérir", "larmes" e "désir") articulados em uma sintaxe que alterna pronomes de primeira e 
segunda pessoa do singular ("tu", "me" e "te") entre funções de sujeito e objeto e encerra a frase com uma pergunta sob forma pronominal: "nous?" O sinal de pontuação a fechar a estrofe postula uma dupla interrogação nesses versos - tanto sobre o conteúdo do poema (se o interlocutor saberia acalentar o eu lírico em dada situação extrema) quanto sobre a possibilidade de haver um "nós" que fundisse gramatical e ontologicamente o "eu" e o "tu" enunciados.

Fechados em si mesmos, tais versos já exibem significativa literariedade; todavia, seus efeitos estéticos se amplificam nas alternâncias vocabulares que o hipertexto aqui enseja. A "indizível/fragrância/da cólera" pode, por exemplo, dar lugar a uma "inalterável/fragrância/da cólera", a uma "indizível/fragilidade/da cólera", ou a uma "indizível/fragrância/ da luxúria”, instanciando uma estrutura rizomática (DELEUZE; GUATTARI, 1997) entre essas combinações que coexistem apenas enquanto potência, posto que só se materializam na não realização de todas as outras possibilidades. Nessa deriva progressiva do original, o poema vai revelando uma alteridade para cada um de seus vocábulos constituintes, de modo a encetar, no nível da materialidade linguística, o mesmo movimento entre o um "eu" e um "tu" (uma palavra e sua substituta no paradigma - ou o eu lírico e seu interlocutor) de que tratam os versos.
Curioso, porém, é pensar que esse jogo poético é, nos termos do verso dois, ao mesmo tempo dizível e indicible (pois cada palavra pode ser lida de uma vez, mas nunca duas delas simultaneamente no mesmo paradigma); alterável e inaltérable (pois cada palavra é comutável por um equivalente paradigmático, mas apenas por este e depois de volta ao original, em um circuito fechado). Todos os elementos linguísticos que compõem a estrutura hipertextual do poema dizem, por conseguinte, tanto de sua imagem poética (a cena amorosa entre "eu" e "tu", no plano do conteúdo) quanto de sua dicção poética (a permuta vocabular, no campo da expressão), instâncias que também se alternam diante dos olhos do leitor. A este cabe, em termos de interpretação, trilhar o sinuoso percurso entre o conteúdo e a expressão que se imbricam, mas, para tanto, tem também de errar entre as relações verbais que se desenrolam no sintagma e no paradigma do poema - ou, nos respectivos eixos metonímico e metafórico a que alude o verso décimo do poema (em que "sinédoque" se alterna com "metáfora").

Ainda no que tange à hipertextualidade que associa as camadas verbais, cumpre ressaltar que o último verso é o único que não apresenta um hover: o diálogo entre a primeira e a segunda pessoa do discurso, que organiza a estrutura multidimensional dessa peça, converge sempre para esse mesmo ponto, que não 
admite alternância - um "nous" que não é "hiperlinkado" a nada. O "nós" que encerra o discurso poético advém da amálgama dos pronomes "tu", "me" e "te", nos versos 5,8 e 9, ou de suas contrapartes ("je", "te" e "me", mediante alternâncias paradigmáticas nos mesmos versos), indicando o único ponto que não se abre à différance para outro signo. Lexia "fixa", em oposição à mobilidade das demais, essa primeira pessoa do plural nasce não de mais uma comutação, mas da fusão de dois seres - ponto de chegada (ou de partida, haja vista o ponto de interrogação) para a poética da alternância que o hipertexto enseja em Alter ego.

\section{Figures: a expansão hipertextual}

Também composta por uma série de telas - numeradas de 00 a 05 em ícones visíveis à direita da interface principal -, Figures apresenta uma arquitetura macrotextual significativamente semelhante à de Alter ego: as telas $00 \mathrm{e} 05$ apresentam paratextos que explicam o funcionamento da obra e o ícone de @ ativa o mesmo serviço de e-mail para que o leitor escreva a mbelisle@scripturae.com. No entanto, diferente da obra analisada na seção anterior deste artigo, Figures é composta não por um único poema, e sim por uma série de quatro textos diferentes, acessíveis apenas por meio da navegação entre as abas 01, 02, 03 e 04. Cada um deles, por sua vez, é formado por uma poética hipertextual que mobiliza a expansão (e não mais a alternância) de novas lexias a cada clique, as quais se justapõem visualmente às anteriores na interface.

Na tela 00, lê-se o seguinte preâmbulo aos poemas de Figures, no qual a autora descreve a lógica que preside à constituição formal de todos eles:

Os textos de "Figuras" ["Figures"] são construídos como uma ilustração literária do Número de Ouro e da sequência de Fibonacci. Como constante matemática e estética, o Número de Ouro constitui uma "matriz" formal que permite determinar o número de palavras e de linhas dos textos assim como a maneira como eles se imbricam um no outro. Os textos de "Figures" são portanto Retângulos de Ouro em que as palavras servem como unidade de medida horizontal e as linhas de unidade de medida vertical (BÉLISLE, 1999, n.p., tradução nossa)

Tal uso de uma "matriz formal" de bases aritméticas como restrição (e, ao mesmo tempo, mola motriz) para a produção textual evidencia na obra de Bélisle clara influência do Oulipo (Ouvroir de Littérature Potentielle) - vanguarda literária francesa da metade do século $\mathrm{XX}$, amiúde tomada como precursora da literatura eletrônica ${ }^{9}$ (RETTBERG, 2019), cujos escritores também lançaram mão de estruturas matemáticas que chamavam de contraintes para condicionar o processo de escrita.

Conforme a descrição que a artista oferece de sua obra, os poemas que a integram são formados a partir do número 
de ouro (mais conhecido como razão áurea $^{10}$, uma constante real algébrica normalmente representada pela letra grega $\phi$ (phi, donde o título "Figures") e não expressável em números inteiros. Ainda segundo Bélisle informa a seus leitores, essa proporção organiza os poemas por meio de relações quantitativas estabelecidas pela sequência de Fibonacci ${ }^{11}$, de modo que o número de palavras em um mesmo verso e o número de versos em uma mesma uma estrofe sejam sempre definidos, em Figures, por dois números consecutivos na célebre sequência de 0 , $1,1,2,3,5,8 \ldots$ (primeiros números da infinita série de Fibonacci).

Para fins de análise, tomemos o primeiro poema da série, intitulado "Figures variables". Ao acessar a tela 01 , por intermédio dos algarismos à direita da interface, o leitor logo vê formar-se um desenho geométrico (Figura 3): a espiral de ouro, linha curva logarítmica cujo fator de crescimento é determinado por $\phi$, a razão áurea.

Figura 3 - Tela inicial de "Figures variables"

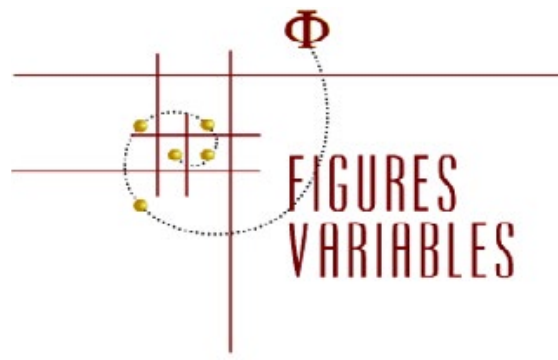

00

| 01

02

03

04

05

Fonte: Bélisle (1999).
Fazendo as vezes de "abertura" do poema, tal imagem é bastante semelhante à que há no início dos demais textos de Figures ${ }^{12}$ ("Figures paralelles", "Figures constantes" e "Figures tangentes”), os quais também exibem a espiral de ouro, mas rotacionada noventa graus para cada novo texto. Desse modo, por meio de uma metáfora simultaneamente geométrica (nas variações da espiral ${ }^{13}$ ) e verbal (nos títulos dos poemas), ressonam visualmente em todos esses textos os temas da repetição na diferença e da diferença na repetição (DELEUZE, 1988), constantes na obra de Bélisle e inerentes às estéticas hipertextuais.

Ao clicar sobre o título, "Figures variables", acede o leitor a nova tela, onde a espiral áurea dá lugar a um dístico:

figures

variables $^{14}$

(BÉLISLE, 1999, n.p.)

Muito embora esse par de versos não introduza informação verbal que não estivesse contida na imagem anterior, a qual já vinha acompanhada das mesmas duas palavras como título do poema, sua leitura é agora condicionada por uma lente analítica introduzida pela imagem da espiral de ouro. Afinal, se a razão áurea é elemento estruturante do poema, ela deve ser entrevista no jogo matemático "em que as palavras servem como unidade de medida horizontal e 
as linhas de unidade de medida vertical (BÉLISLE, 1999, n.p., tradução nossa)". Assim, ganha valor estético numérico, e não puramente linguístico, o fato de haver uma palavra em cada verso, num total de dois versos nessa estrofe, a qual, na proporção $1: 2$, indica a presença de dois valores consecutivos na sequência de Fibonacci.

Ao clicar sobre qualquer das duas palavras, o leitor desencadeia a ação de um hiperlink, o qual, em vez de substituir esses vocábulos por outros (no que chamáramos antes de poética da alternância), causa a expansão dos versos em sintagmas mais longos, acrescentando-se-lhes novos signos. Dá-se, assim, origem a um novo dístico, que contém o anterior, mas modifica-o ao alargá-lo:

\section{figures et mouvements}

variables du plaisir ${ }^{15}$

(BÉLISLE, 1999, n.p., grifo nosso)

Na comparação entre o dístico anterior e o novo - movimento interpretativo a que o leitor é conduzido pela expansão dos versos diante de seus olhos -, chamam a atenção os efeitos de sentido aportados pelos novos substantivos: "mouvements" e "plaisir". Tais palavras ressignificam a imagem das "figuras variáveis”, adicionando-lhe uma conotação quiçá sexual pela alusão ao vaivém prazeroso dos corpos. Essa dimensão viva atribui também novos sentidos à palavra "figures", pois, se antes esta designaria apenas figuras geométricas, tal qual a espiral áurea, agora se reveste de outra acepção prevista na língua francesa: a ideia de rosto. Trata-se, então, das faces (termo a meio do caminho entre o geométrico e o fisionômico) dos amantes, em seus movimentos de prazer.

Curioso é notar que, a reboque das reconfigurações semânticas que essa hiperpoética da expansão impõe a cada um dos vocábulos do dístico, são também transformadas as relações sintáticas que entre eles há, o que revela intrincada homologia entre os estratos tradicionais da fenomenologia da poesia, descritos por Ramos (1974), e o estrato hipertextual. Assim, se antes apenas as figuras eram variáveis, agora se tem "figuras e movimentos/ variáveis do prazer", em que se pode ler "variáveis do prazer" como adjunto adnominal que modifica apenas "movimentos"; como adjunto adnominal que modifica "figuras e movimentos"; ou como aposto a dizer "figuras e movimentos (que são) variáveis do prazer". Nesse último caso, a expansão dos versos implicaria uma mudança gramatical para "variáveis", deixando o termo de ser adjetivo para passar a substantivo atinente ao campo semântico da Matemática.

Ainda no diapasão que a razão áurea impõe à leitura do poema, cumpre ressaltar que, a esta altura da navegação, tem o leitor acesso a três palavras em cada um dos dois versos, o que implica uma 
nova razão (3:2), a envolver, mais uma vez, números consecutivos de Fibonacci.

Novo clique no hiperlink sob a materialidade verbal implica consequente re-expansão do poema, em moldes análogos à anteriormente descrita. No entanto, desta feita o aumento não é na quantidade de palavras por verso, e sim na quantidade de versos por estrofe, de modo que o dístico de então se estende para o seguinte quinteto:

\section{nous voilà presque}

\section{éperdus de certitude}

égarés dans les

figures et mouvements

variables du plaisir ${ }^{16}$

(BÉLISLE, 1999, n.p., grifos nossos)

A esta altura na navegação, o crescimento da estrofe enseja a apresentação de um novo contexto para a imagem contida anteriormente no dístico: "as figuras e movimentos/ variáveis do prazer" indicam agora explicitamente algo da dinâmica entre dois amantes perdidos no desejo, aludidos por meio do pronome "nous" (tal qual em Alter ego). Contudo, diferente do ocorrido na expansão anterior, neste momento a reconfiguração da imagem não se dá por alterações em relações sintáticas ou semânticas, e sim pela introdução de uma moldura que associa os dois últimos versos a uma cena amorosa, o que corrobora a supracitada ambiguidade do substantivo "figures" no poema.

Ainda no que tange à duplicidade de sentidos nos versos, note-se que os termos "éperdus de certitude" e "égarés", que indicam o estado de perturbação dos amantes diante das "variáveis do prazer", também podem ser lidos como referência à potencial desorientação advinda da leitura de um texto que não permanece igual a si, graças à poética da expansão de "figuras variáveis" engendradas pelos hiperlinks. Nessa expansibilidade (e consequente transformabilidade da matéria verbal e de seu suporte), "Figures variables" confirma que deve, de fato, ser lido como (hiper) texto, e não como obra, se estendermos a terminologia de Barthes (1994) para o meio digital.

Em termos quantitativos, mais uma vez a razão áurea é contrainte que determina não só a organização dos versos, mas também sua interpretação: nessa estrofe, temos três palavras em cada um dos cinco versos - novamente, dois números consecutivos na série de Fibonacci. E, se o leitor clicar em novo hiperlink nesse quinteto, assiste à sua expansão para outra estrofe de cinco versos, mas agora com oito palavras - e eis-nos ainda em meio aos números fibonaccianos. Este é o último quinteto no processo de expansão progressiva do texto: 
malgré ce qui survit en nous, voilà presque

advenu l'âge des toujours; éperdus de certitude

comme si nous nous étions égarés dans les

métaphores, nous croyons que les figures et mouvements

du langage remplacent les mobiles variables du plaisir $^{17}$

(BÉLISLE, 1999, n.p., grifos nossos)

Nessa estrofe, os três primeiros versos continuam situando um contexto para a leitura da imagem contida nos dois últimos versos. No entanto, a essa moldura inicial são aqui acrescidas por hipotaxe construções que garantem certa temporalidade memorialística à cena, aludindo ao "que sobrevive em nós" e à "chegada [d]a idade de sempre", o que é reforçado pela marcação de l'imparfait, como tempo verbal, na locução "étions égarés".

Em paralelo a essas mudanças que complexificam a relação amorosa de que trata o eu lírico, as alterações na segunda metade da estrofe fazem com que $o$ casal deixe de estar perdido "nas figuras e movimentos/variáveis do prazer". Com a expansão dos versos, o enjambement iniciado por "dans les" não é mais articulado a "figures" e "mouvements", pois passa a se relacionar com "métaphores". Tal deslocamento das relações sintáticas sublinha a dimensão metapoética do texto e o fato de os desencontros entre um casal serem da ordem não só do corpo, mas também da linguagem. Nesse sentido, são reveladores os dois últimos versos do poema, segundo os quais "as figuras e movimentos/ da linguagem substituem as variáveis móveis do prazer". Nessa passagem do gozo carnal ao verbal, movem-se as formas de os amantes se vincularem um ao outro; movem-se as formas de uma palavra se vincular à outra (por consequência das expansões dos versos); e movem-se as formas de uma lexia se vincular à outra por hiperlinks (da alternância à expansão, como analisamos nesta seção).

\section{Lames: a redistribuição hipertextual}

Última produção analisada neste artigo, Lames é também uma série de breves hiperpoemas organizados em abas numeradas de 00 a 03 (e, mais uma vez, seguidas do ícone de arroba, para envio de mensagem à artista). Nas telas de 01 a 03, o leitor acessa os três poemas que integram a série, intitulados, respectivamente, "Feintise" ("fingimento"), "Morsure" ("mordida") e "Vanité" ("vaidade"), os quais mobilizam recursos hipertextuais não para imprimir relações de alternância ou de expansão, mas sim de redistribuição dos signos da interface. 
Tal dinâmica semiótica é perceptível desde a tela 00 , paratexto a exibir uma rápida animação em que, partindo de um palimpsesto de grafismos sobrepostos, deslizam letras em caixa alta para formar a palavra LARMES (em português, "lágrimas"), em tipos de linhas quebradas e acompanhadas por pequenos fragmentos. Se a relação entre o significante tipográfico e o significado verbal não é evidente num primeiro momento, sua articulação se deslinda na sequência da animação: um ícone de instrumento pontiagudo aparece na tela e risca, em linhas vermelhas, os espaços entre A e $\mathrm{R}$ e entre $\mathrm{R}$ e $\mathrm{M}$ (Figura 4), de modo a extirpar a terceira letra da palavra e formar o substantivo LAMES (em português, "lâminas"). Os tipos em linhas quebradas, bem como o título da série, remetem, afinal, às operações de cisão e reordenação de signos engendradas por meio de recursos hipertextuais.

Figura 4 - Tela inicial de "Lames"

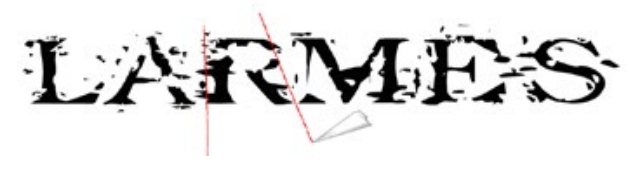

Fonte: Bélisle (1999)

Tal jogo entre corte e colagem de grafemas - em última medida, indissociável das dinâmicas de corte e colagem entre textos, que Compagnon (1996) associou às práticas intertextuais - devém, em Lames, o compasso das práticas hipertextuais que a obra engendra. Nesse sentido, é particularmente interessante o segundo hiperpoema da série, intitulado "Morsure", no qual a imagem do talho comparece simultaneamente nos planos da expressão e do conteúdo. Como veremos a seguir, entre tais planos se operam, por ação de hiperlinks, forças centrífugas que fraturam as lexias, mas que reequilibram o sistema por forças centrípetas a rearticular essas partes fracionadas.

Ao navegar entre as diferentes abas de Lames, se o leitor clicar no ícone 02 à direita da interface, é levado a uma nova tela, na qual se justapõem, horizontalmente, o título de "Morsure", sua estrofe-matriz (a partir da qual outras são formadas) e o mesmo ícone designativo de um palimpsesto que já fora encontrado na tela inicial da série. Tal estrutura, bem como os efeitos de animação dos versos a serem desencadeados por hiperlinks, se repetem nos outros dois poemas de Lames, compondo uma hiperpoética da redistribuição de seus signos. Para fins de análise, transcreve-se abaixo a estrofe-matriz de "Morsure", sobre cujos versos incidem os efeitos redistributivos ativados pelos cliques do leitor. 


\section{morsure}

jusqu'à la mort, la pointe

précise le mensonge du baiser sur la taille du petit cri dur et adamantin comme le paradoxe solitaire du toucher,

qui se casse tel un émail qui, sourd, jusque là, mord ${ }^{18}$

(BÉLISLE, 1999, n.p.)

Logo no primeiro verso, a referência à morte define o tom da estrofe, a qual é lida sob os semas da dor e da finitude, presentes também em signos como "mensonge" ("mentira"), "petit cri dur et adamantin" ("pequeno grito duro e adamantino"), "paradoxe solitaire" ("paradoxo solitário") e "se casse tel un émail" ("se quebra qual um esmalte"). Tal imagem se adensa na medida em que é atravessada também por alusões a cortes e perfurações, em termos como "pointe" ("ponta"), "taille" ("talho") e "mord" ("morde"), sendo a relação entre as ideias de cesura e falecimento ressaltada por uma ligação paradigmática e paragramática (KRISTEVA, 2005) de ordem não eletrônica, como nos hiperlinks, mas sonora, como na rima, entre os homófonos "mort" e "mord". Morrer e morder são, afinal, contrafaces de uma mesma moeda no poema, cujo título também pode ser lido na homofonia entre "morsure" ("mordida") e "mort sûre" ("morte segura") - ou mesmo na paronímia com o sintagma "morte sourde" ("morte surda"), que não se realiza no texto, mas é sugerido pela presença do adjetivo "sourd" ("surdo") no último verso.

Tais trocadilhos, a que se acrescenta aquele que se estabelece entre "jusqu'à la" (“até à"), no primeiro verso, e "jusque là" ("até então"), no último, marcam reiteradamente imagens de cortes e as consequentes fronteiras que todo talho abre. No poema, as lâminas do título, com que se efetuam as incisões na carne e no verbo, são também os dentes cujo esmalte aparece no penúltimo verso, o que amplifica a associação entre a incisão (ou os incisivos), a boca e a língua - instrumentos de produção de linguagem (na articulação dos fonemas) e de separação (no ato da mastigadura).

Se já é rica o bastante a imagem poética construída pelo código verbal nessa estrofe, seus efeitos se amplificam ainda mais quando entremeados à mobilidade dos elementos conectados por nós na hipermídia (LANDOW, 1992) - blocos disjuntos, afinal, como se entre eles se tivessem operado também cortes semióticos -, que o leitor ativa por meio de um clique sobre os versos. Ao fazê-lo, desencadeia novo efeito da animação em Flash, dando a ver mais uma vez o ícone do instrumento pontiagudo cortante da Figura 4, mas agora cindindo cada um dos versos com um corte em linha poligonal. Nesse processo, as palavras de "Morsure" são redistribuídas em duas estrofes lado a lado, cada uma contendo pedaços dos versos anteriores (Figura 5). 
Figura 5 - Tela de "Morsure", da série "Lames

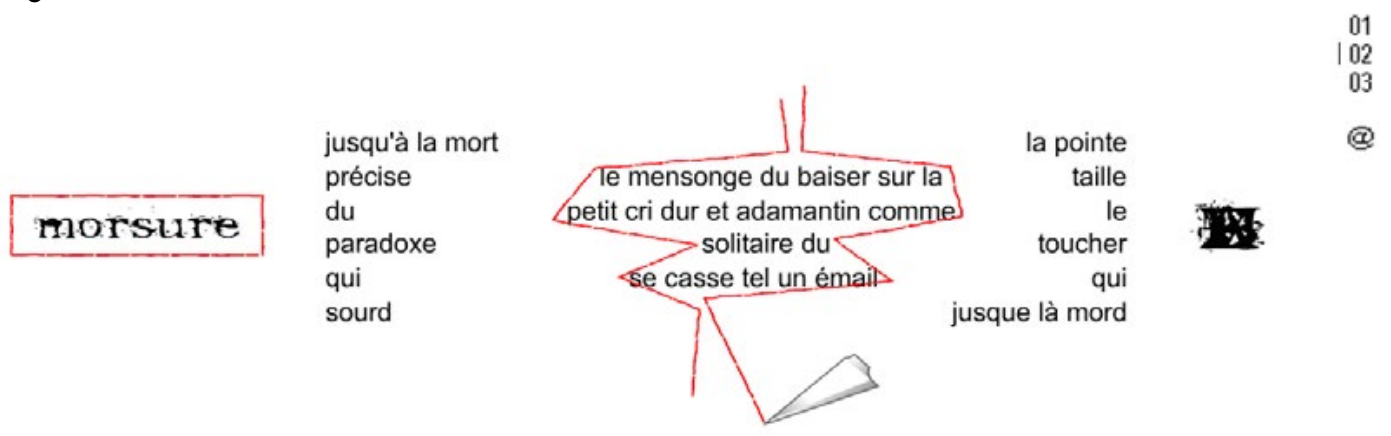

Fonte: Bélisle (1999)

Nessa imagem, nota-se o primeiro efeito da poética de redistribuição que $o$ hiperlink engendra no poema: desmembradas em estrofes e versos separados, as palavras de "Morsure" contraem novas relações sintático-semânticas. De tal sorte, a estrofe à esquerda passa a falar da "morte/precisa/do paradoxo/que/surge", em que a cisão gráfica nos versos explicita (ou torna mais precisos) os paradoxos da língua poética, e o termo "sourd", que na estrofe anterior funcionava como 0 adjetivo "surdo", se ressignifica como flexão homônima do verbo "sourdre" ("surgir"). De modo análogo, a estrofe à direita, a qual aponta para o fato de que "a ponta/ talha/o/tocar/que/até então morde”, conota a excisão a que o verbo é submetido nas articulações da língua e da poesia; "taille" passa, então, a funcionar como flexão do verbo "tailler", indicando não mais o objeto do beijo, senão a ação da ponta que fende uma superfície.

Novamente, a relação entre as duas estrofes - em que a segunda remete ao corte gráfico condicionador dos paradoxos linguísticos mencionados na primeira -, é reforçada pela conexão virtual que a semelhança fônica constrói entre o primeiro verso à esquerda (“jusqu'à la mort") e o último verso à direita ("jusque là, mord"), em um jogo de meio quiasma. Dificilmente, porém, pode o leitor chegar a essas ilações enquanto assiste à animação: a transição entre os estados da interface é muito rápida, de modo que, apenas após repetidas execuções se tornam perceptíveis as intrincadas conexões que se redistribuem entre as palavras. Sem executar várias vezes o poema, ou sem recorrer a ferramentas externas de captação de imagens (como o recurso do print screen, repetidamente utilizado neste artigo), não tem o leitor tempo para profundos exercícios interpretativos, dado que a tela visível na Figura 5 logo dá lugar à que se reproduz na Figura 6, ainda por ação do mesmo hiperlink, culminando em outra reorganização espacial dos signos: 
Figura 6 - Tela de "Morsure", da série "Lames"

\section{morsure}

jusqu'à la mort précise du paradoxe qui sourd,

la pointe taille le toucher qui, jusque là, mord

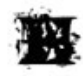

Fonte: Bélisle (1999)

Essa tela, que encerra o poema em questão, dá a ler as mesmas palavras que compunham as duas estrofes da tela anterior (que, por sua vez, integravam a estrofe-matriz do poema), mas dispostas em outra sintaxe espacial. Esta, rearranjado visualmente os signos, implica uma mudança também na sintaxe verbal, dado que, pela operação hipertextual de redistribuição, as palavras agora se alinham em um dístico concatenado por hipotaxe. Nesse par de versos, o primeiro, composto pela justaposição horizontal dos termos oriundos da estrofe até então à esquerda, assume a função de oração temporal que enquadra a imagem do segundo verso, determinando que, até a morte do paradoxo (in)surgente, reiterem-se o talhos e mordidas da ferramenta pontiaguda.

Tal instrumento, na medida em que decepa os versos de "Morsure" por ação do ícone de uma ponta cortante - isto é, de afiada lâmina, como no título da série hiperpoética em questão -, deixa para trás apenas um rastro, um traço, um gramma (DERRIDA, 1973), que se manifesta visualmente nas linhas vermelhas da Figura 6 e nas conexões eletrônicas que o recurso ao hiperlink mobiliza na obra: marcas de excisão e recombinação de elementos, como bem faz toda rede textual.

\section{Considerações finais}

Ao longo deste artigo, realizou-se minucioso exercício de close reading das obras hiperpoéticas Alter ego, Figures e Lames, da artista quebequense Marie Bélisle, a fim de investigar os singulares usos poéticos da tecnologia de hiperlink nos textos da autora. Tal análise considerou a relação íntima entre os planos do conteúdo e da expressão verbal no corpus, quando atravessados por outras relações semióticas que não as entre palavras: as conexões eletrônicas entre telas por meio da ferramenta Flash.

Como resultado desta empreitada analítica, destaque-se uma proposta (ainda inicial) de vocabulário técnico 
para descrever os efeitos de sentido que os hiperlinks imprimem à articulação do material verbal nos hiperpoemas de Bélisle, por meio de relações de alternância, expansão e redistribuição dos signos. Muito embora o corpus seja pequeno demais para permitir qualquer forma de generalização, tais categorias têm o potencial de fornecer subsídios a estudos posteriores, os quais podem vir a testar sua aplicabilidade para outros contextos, obras e formatos.

Cumpre ressaltar que, nas três produções analisadas, os semas de alternância, expansão e redistribuição não se limitam às formas de conexão eletrônica entre as lexias, pois se revelam parte integral das imagens constituídas por meio da linguagem verbal. Trata-se de característica que permeia toda a obra de Bélisle, cuja atenção para a homologia entre os diferentes estratos poéticos (RAMOS, 1974) e o estrato hipertextual é evidente. No mesmo diapasão, é digno de nota que todos os hiperlinks nos poemas aqui analisados desencadeiam não apenas alterações quanto ao aparece ou não na interface, mas também mudanças nas relações sintático-semânticas contraídas entre as palavras.

Por fim, é digno de nota que, embora as teorias mais tradicionais de hipertexto refiram-se a essa forma de organização textual apontando para sua potencial infinitude, por meio de novos hiperlinks que possam ser criados pelo autor ou pelo leitor a qualquer momento, essa é uma possibilidade técnica não implementada em Alter ego, Figures ou Lames. Nas três produções, o universo navegável pelo leitor é finito - e bastante conciso, em comparação com a extensão tradicional da hiperficção, no que parecem ressonar as postulações de Cohen (1970) acerca da concisão da linguagem poética. Esta, aliás, parece também poder fazer do hipertexto sua morada, como nossas análises evidenciam; resta-nos, pois, empreender esforços para melhor compreender as formas e procedimentos pelos quais a poesia se transforma em hiperpoesia por meio de recursos eletrônicos cada vez mais difundidos na web.

\section{Poetic singularities of hyperconnection: the use of electronic links in poems by Marie Bélisle}

\section{Abstract}

Despite its relevance in the history of the concepts of text and digital technologies, the notion of hypertext is frequently deprived of its meanings in academy, either due to the semantic inflation it undergoes to name very different language dynamics or due to the fact that almost all discourses on the Internet are hypertexts/ hypermedia. More specifically relating to electronic literature - an increasing artistic field - research has to go beyond acknowledging the hypertextual organization of digital works; therefore, they must understand the 
singular poetic operations engendered by hypertext and their respective meaning effects. To do so, this article proposes an analysis of hyperpoems from Alter ego, Figures e Lames, developed in Flash by the Quebecker artist Marie Bélisle. In this study, we focus on the poetic operations engendered by hyperlinks, by proposing a categorization of hypertextual poetics into procedures of alternation, expansion and redistribution.

Keywords: Hypertext; Hyperpoems; Marie Bélisle

\section{Notas}

1 Genette (1982) usava o termo "hipertexto" para designar quaisquer textualidades que derivassem de escritas anteriores, fosse por transformação ou imitação.

2 Software desenvolvido e comercializado pela empresa Macromedia para criação de animações interativas para a web.

3 Embora o catálogo atual da editora conte com alguns títulos de poesia hipertextual, como True North, de Stephanie Strickland, e My Name Is Captain, Captain, de Judd Morrisey e Lori Talley, o fato de os mesmos estarem acessíveis somente mediante compra online de CDs contendo as obras (numa época em que o CD já se torna mídia obsoleta) impõe severo obstáculo à sua circulação em contraponto à abundância de hiperficções gratuita e facilmente acessíveis na Internet.

4 Santos (2013) diz ser esta uma operação necessária que antecede o ato interpretativo em textos experimentais - tanto os eletrônicos quanto os que os antecedem, ainda em mídia impressa, em estéticas como a do barroco ibérico, a da poesia experimental portuguesa ou a da poesia concretista brasileira. Textos desta natureza exigiriam ao leitor um esforço cognitivo primeiro para reconhecer suas formas de organização e consumo antes da leitura propriamente dita e da interpretação.

5 Sendo esse ícone também marcador de um hiperlink, que abre uma ferramenta de envio de e-mails no computador do usuário, seus efeitos estéticos são de interação não apenas com o tex- to poético, mas também com a artista por trás dele. Cumpre ressaltar que, muito embora tal comunicação se dê num plano "extraliterário", isto é, por meio de uma tecnologia de comunicação que não o poema de Bélisle, a interação é ensejada por um signo e um hiperlink que fazem parte da macroestrutura do poema. Trata-se, pois, de fenômeno ao mesmo tempo externo e interno ao texto, embaralhando essas categorias frequentemente pressupostas como axiomas nos Estudos Literários. O fato de que todos os poemas da autora no site apresentam o mesmo tipo de hiperlink, sob o mesmo signo (a arroba), ratifica sua relevância para a análise ora empreendida.

6 Hover, ou mouse-over, é um tipo de recurso eletrônico que desencadeia um efeito gráfico toda vez que o cursor passa por uma área específica da interface (por exemplo, uma imagem ou palavra que aparece quando o ponteiro do mouse desliza sobre um hiperlink em uma página da Internet).

7 Tradução livre: Na/indizível/fragrância/da cólera,/tu saberias me acalentar/até que/as lágrimas do desejo/me dilacerem/e te entreguem a/ essa dupla sinédoque:/nós?

8 Tradução livre: Sem a/inalterável/fragilidade/ da luxúria,/eu poderia te ferir/mesmo que/as armas da dúvida/te toquem/e me livrem de/ essa doce metáfora/nós?

$9 \quad$ Entre as obras de artistas oulipianos que mais frequentemente são associadas à literatura eletrônica, são dignas de nota Cent milles milliards de poèmes, de Raymond Queneau, de 1961, por seu cariz combinatório; Se um viajante numa noite de inverno, de Italo Calvino, de 1979, por sua organização hipertextual; e $L a$ disparition, de George Perec, de 1969, por sua composição a partir de um rigoroso algoritmo lexical: a exclusão de quaisquer palavras que contivessem a letra $\mathrm{E}$.

10 De longa história nas áreas da Geometria, da Arquitetura e das Artes Plásticas - e muito em voga no Renascimento -, a razão áurea indica uma certa proporção entre elementos, na razão de, aproximadamente, 1,618; esta, supostamente, representaria o ápice em termos de equilíbrio e proporção nas artes, podendo ainda ser encontrada na natureza em relações numéricas como as que há entre as dimensões de partes do corpo humano, ou entre a quantidade de brotos em uma planta em desenvolvimento.

11 Os célebres números de Fibonacci compõem uma sequência de números inteiros que gra- 
dativamente se aproximam da razão áurea na medida em que um termo (n) e seu antecessor (n-1) são relacionados por meio de uma razão $\mathrm{n} / \mathrm{n}-1$.

12 A poética de uma hipertextualidade por expansão de signos, ora descrita para o caso de "Figures variables", se encontra também nos demais poemas da série Figures. $\mathrm{O}$ que distingue os quatro poemas da série é principalmente o material linguístico submetido ao experimentalismo com os hiperlinks.

13 Há que se dizer que, como matriz epistemológica, a imagem da espiral (ou da dobra) também é cara às discussões do hipertexto eletrônico, em sua ressonância da teoria de Deleuze (1991) e em seu uso metafórico para tratar do "desdobramento" das lexias que residem, em estado de potência, sob um hiperlink.

14 Tradução nossa: figuras/variáveis.

15 Tradução nossa: figuras e movimentos/variáveis do prazer.

16 Tradução: eis-nos aqui quase/ perturbados de certeza/ perdidos nas/ figuras e movimentos/ variáveis do prazer.

17 Tradução nossa: apesar do que sobrevive em nós, eis-nos aqui quase/ chegada a idade de sempre; perturbados de certeza/ como se nós nos tivéssemos perdido nas/metáforas, nós cremos que as figuras e movimentos/da linguagem substituem as variáveis móveis do prazer.

18 Tradução nossa: até a morte, a ponta/ determina a mentira do beijar no talho/ do pequeno grito duro e adamantino como o/ paradoxo solitário do tocar,/ que se quebra qual um esmalte que,/ surdo, até então, morde.

\section{Referências}

BARBOSA, Pedro. A renovação do experimentalismo literário na Literatura Gerada por Computador. Revista da UFP, v.2, n.1, p. 181-188, 1998.

BARTHES, Roland. Euvres complètes. v.2. Paris: Seuil, 1994.

BÉLISLE, Marie. Scriptura et Caetera. 1999. Disponível em: http://www.scripturae.com/ CadresScript.htm. Acesso em: 20 nov. 2019.

BUTTERFIELD, Andrew; NGONDI, Gerard Ekembe; KERR, Anne. A Dictionary of
Computer Science. Oxford: Oxford University Press, 2016.

COHEN, Jean. Estructura del lenguaje poético. Madrid: Gredos, 1970.

COMPAGNON, Antoine. O trabalho da citação. Belo Horizonte: Editora UFMG, 1996.

DELEUZE, Gilles; GUATTARI, Félix. Mil platôs: capitalismo e esquizofrenia. Rio de Janeiro: Editora 34, 1997.

DELEUZE, Gilles. A dobra: Leibniz e o barroco. Campinas: Papirus, 1991.

DELEUZE, Gilles. Diferença e repetição. Rio de Janeiro: Graal, 1988.

DERRIDA, Jacques. Gramatologia. São Paulo: Perspectiva, 1973.

DERRIDA, Jacques. Marges de la philosophie. Paris: Minuit, 2003.

ELMCIP - Electronic Literature as a Model of Creativity and Innovation in Practice. 2019. Disponível em: https:/elmcip.net/. Acesso em: 20 out. 2019 .

ELO - Electronic Literature Organization. Electronic Literature Collection. v. 1. 2006. Disponível em: http://collection.eliterature. org/1/. Acesso em: 1 nov. 2019.

ELO - Electronic Literature Organization. Electronic Literature Collection. v. 2. 2011. Disponível em: http://collection.eliterature. org/2/. Acesso em: 1 nov. 2019.

ELO - Electronic Literature Organization. Electronic Literature Collection. v. 3. 2016. Disponível em: http://collection.eliterature. org/3/. Acesso em: 1 nov. 2019.

FUNKHOUSER, Chris. New Directions in Digital Poetry. New York: Continuum, 2012.

GENETTE, Gérard. Palimpsestes: la littérature au second degré. Paris: Seuil, 1982.

HAYLES, Katherine. Electronic Literature: What is it? Electronic Literature Organization. V1.0. 2 jan. 2007. Disponível em: http:// eliterature.org/pad/elp.html. Acesso em 02 nov. 2019. 
HAYLES, Katherine. Literatura eletrônica: novos horizontes para o literário. São Paulo: Global, 2009.

HAYLES, Katherine. My Mother Was a Computer: Digital Subjects and Literary Texts. Chicago: University of Chicago Press, 2005.

JAKOBSON, Roman. Linguística e comunicação. São Paulo: Cultrix, 1985.

JENKINS, Henry. Cultura da convergência: a colisão entre os velhos e novos meios de comunicação. São Paulo: Aleph, 2009.

KRISTEVA, Julia. Introdução à semanálise. São Paulo: Perspectiva, 2005.

LANDOW, George Paul. Hypertext: The Convergence of Contemporary Critical Theory and Technology. Baltimore: John Hopkins University Press, 1992.

MANOVICH, Lev. The Language of New Media. Cambridge: MIT Press, 2001.

PAZ, Octavio. Signos em rotação. São Paulo: Perspectiva, 1996.

RAMOS, Maria Luíza. A fenomenologia da obra literária. Rio de Janeiro: Forense Universitária, 1974.

RETTBERG, Scott. Electronic Literature. Cambridge: Polity, 2019.

SANTOS, Alckmar Luiz dos. Leituras de nós: Ciberespaço e literatura. São Paulo: Itaú Cultural, 2003. 